\title{
AVALIAÇÃO DA PERCEPÇÃO AMBIENTAL DE MORADORES DA MALHA URBANA DE PRESIDENTE PRUDENTE
}

Diego A. Mendes Nascimento ${ }^{1}$, Juliana Mayumi Cihoda ${ }^{1}$, Leila Maria Sotocorno e Silva ${ }^{1}$, Raoni Oliveira Souza $^{2}$

${ }^{1}$ Discente de Graduação - UNOESTE. ${ }^{2}$ Docente - UNOESTE

\section{RESUMO}

A preocupação com as questões ambientais vem se tornando prioridade nos países em desenvolvimento, no entanto, ainda não é tão evidente a correta percepção que os indivíduos evidenciam sobre o assunto. 0 projeto elaborado tem como objetivo avaliar o nível de percepção ambiental dos participantes do evento Interação e realizar trabalho de educação ambiental. Foi aplicado questionário, de maneira aleatória, ao público participante do evento, contendo 4 questões relativas aos problemas ambientais existentes em seu bairro. Foi entrevistado um total de 153 pessoas, na faixa etária de 6 a 70 anos, em sua grande maioria moradores de bairros da periferia do município de Presidente Prudente. Pode-se concluir que embora o nível de percepção ambiental dos entrevistados não tenha se mostrado satisfatório, de maneira geral, a maior parte deles demonstrou disponibilidade em ajudar o meio ambiente.

Palavras-chave: Interação, Percepção Ambiental, Educação Ambiental.

\section{EVALUATION OF ENVIRONMENTAL PERCEPTION OF RESIDENTS IN PRESIDENTE PRUDENTE}

\section{ABSTRACT}

The concern about environmental issues is becoming prior in developing countries, however, it's no yet so evident the correct perception that people gave to the subject. This project has the objective to estimate the environmental perception level of the participants of Interact event and do an environmental education job. Was applied a questioner, randomly, to the public in event, containing 4 questions about environmental issues in his neighborhood. Were interviewed 153 peoples, in 6 to 70 years, mostly of them in the periphery of Presidente Prudente. We can conclude that their level of perception about environmental issues was not satisfactory but in a general way, most of them show availability in help the environment.

Key words: Interaction, Environmental Perception, Environmental Education. 


\section{INTRODUÇÃO}

A preocupação com as questões ambientais vem se tornando prioridade nos países em desenvolvimento, sobretudo, a partir da Conferência das Nações Unidas sobre Meio Ambiente e Desenvolvimento (RIO 92), realizada na cidade do Rio de Janeiro em julho de 1992.

Após esse evento, muito se falou e vem se falando sobre meio ambiente no Brasil, no entanto, ainda não é tão evidente a correta percepção que os indivíduos evidenciam sobre o assunto, principalmente em relação a real dimensão das variáveis ambientais e seus efeitos sobre o ambiente como um todo. (FERNANDES et al., 2006).

A percepção ambiental pode ser definida como sendo uma tomada de consciência do ambiente pelo homem, ou seja, o ato de perceber o ambiente que se está inserido, aprendendo a proteger e a cuidar do mesmo (FAGGIONATO, 2002)

Cada indivíduo percebe, reage e responde diferentemente às ações sobre 0 ambiente em que vive. Sendo assim, é de fundamental importância o estudo da percepção ambiental a fim de que se possa compreender melhor as inter-relações entre o homem e o meio ambiente, suas expectativas, satisfações e insatisfações, julgamentos e condutas. (FERNANDES et al., 2006).

Através da avaliação do nível de percepção ambiental de um grupo de pessoas é possível compreender o posicionamento dos mesmos diante das mazelas ambientais às quais estão sujeitos e colocar em prática trabalhos de educação ambiental que sejam pertinentes à realidade observada, garantindo-se, assim, o sucesso dos mesmos.

Um dos principais objetivos da educação é levar a ações de transformações da sociedade em bases mais justas, com maior equidade, mais democráticas e sustentáveis. Assim, cabe à educação ambiental construir novos valores e novas relações sociais e dos seres humanos com a natureza, formando atitudes dentro de uma nova ótica, a da melhoria da qualidade de vida para todos os seres. (PHILIPPI JUNIOR; PELICIONI, 2002).

Dentro deste contexto o escopo deste trabalho é avaliar o nível de percepção ambiental dos participantes do evento Interação realizado no Bairro Vila Furquim em setembro de 2009 no município de Presidente Prudente e realizar trabalho de educação ambiental junto ao público participante do evento.

\section{MATERIAIS E MÉTODOS}

Com o intuito de avaliar a percepção ambiental do público participante do evento e realizar trabalho de educação ambiental foram realizadas as etapas que serão mais bem detalhadas a seguir.

\subsection{Evento}

O Interação, evento a que se refere o presente artigo, foi organizado pela Prefeitura Municipal de Presidente Prudente, Serviço Social da Indústria (SESI) em parceria com a TV Fronteira e a Universidade do Oeste Paulista (UNOESTE). Foi realizado em 19 de setembro de 2009, das 9:00h às 16:00h no bairro Vila Furquim localizado no município de Presidente Prudente, contando com um público estimado de 15.000 pessoas.

O evento tinha como público alvo moradores da periferia da cidade de Presidente Prudente, sobretudo, moradores dos bairros próximos ao SESI localizado na Vila Furquim.

O Interação trata-se de um mutirão de solidariedade e caracteriza-se por prestar atendimento, sobretudo a pessoas carentes, através de serviços nas seguintes áreas: Direito, Medicina, Educação Física, Odontologia, Enfermagem, Farmácia, Nutrição, Fisioterapia, 
Medicina Veterinária, Agronomia, Engenharia Ambiental, Turismo, Fonoaudiologia e Informática.

\subsection{Serviço prestado}

A equipe responsável pela prestação de serviços na área ambiental durante o evento Interação foi composta por 9 pessoas sendo: 6 alunos da Universidade do Oeste Paulista (UNOESTE), 4 deles pertencentes ao curso de Engenharia Ambiental e os demais ao curso de Agronomia, 2 alunos do curso técnico do Colégio Agrícola de Presidente Prudente e 1 docente do curso de Engenharia Ambiental da UNOESTE.

O trabalho realizado pode ser dividido em 2 partes: avaliação do nível de percepção ambiental e atividades de educação ambiental, como será detalhado a seguir.

\subsubsection{Avaliação do nível de percepção ambiental}

Com o intuito de avaliar a percepção ambiental do público participante do evento foi elaborado um questionário contendo 4 questões de múltipla escolha através do qual o entrevistado deveria apontar a existência ou não de problemas ambientais em seu bairro, suas causas e de que maneira os mesmos poderiam ser resolvidos.

Os questionários foram aplicados de maneira aleatória ao público que visitou o stand do Meio Ambiente.

\subsubsection{Educação Ambiental}

O trabalho de educação ambiental contou com a apresentação de slide, distribuição de mudas de árvores e imas de geladeira, como é apresentado em seguida.

\subsubsection{Apresentação de Slides}

O trabalho de educação ambiental contou com uma apresentação de slides, a qual foi realizada com o auxílio de aparelho multimídia.
Foram apresentados ao público imagens e vídeos que mostravam a importância das pessoas no meio em que vivem, e sua responsabilidade na alteração desse meio, quer seja de maneira benéfica ou adversa, salientando-se assim a importância da adoção de práticas mais sustentáveis em seu dia-a-dia.

\subsubsection{Distribuição de Imã de Geladeira}

Durante o evento foram distribuídos imãs de geladeira confeccionados com materiais reciclados - caixas de leite, imã de porta de geladeira e papel reciclado.

$\mathrm{O}$ intuito da entrega dos imãs era sugerir às pessoas atitudes que poderiam ser incorporadas em seu cotidiano para uma "vida mais sustentável", tais como - banhos menos demorados, adesão à Programa de Coleta Seletiva, racionalização de água, utilização de produtos de limpeza biodegradáveis, entre outros.

\subsubsection{Distribuição de Mudas de Árvores}

Foram distribuídas mudas, de cinco espécies distintas, doadas pela Secretaria de Meio Ambiente do município de Presidente Prudente e Universidade do Oeste Paulista (UNOESTE).

A distribuição das mudas era condicionada ao preenchimento do questionário.

\section{RESULTADOS E DISCUSSÃO}

Foram entrevistados um total de 153 pessoas, na faixa etária compreendida entre 6 e 70 anos, em sua grande maioria moradores de bairros pertencentes à periferia do município de Presidente Prudente, como mostra a Figura 1. 


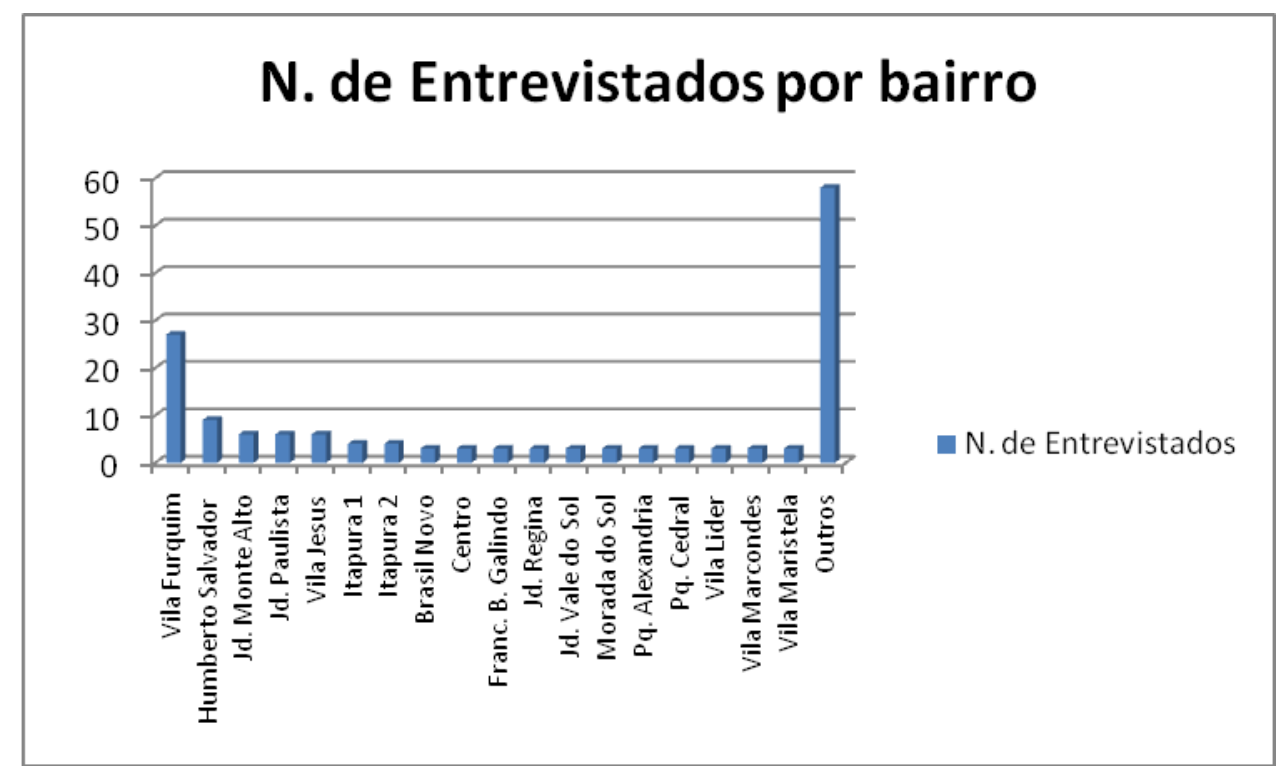

FIGURA 1 - Levantamento de numero de entrevistados por bairro

Os dados obtidos no questionário mostraram que $16 \%$ dos entrevistados não apontaram problema algum em seus bairros enquanto $84 \%$ relatam a ocorrência de ao menos um tipo de problema ambiental, como mostra a Figura 2.

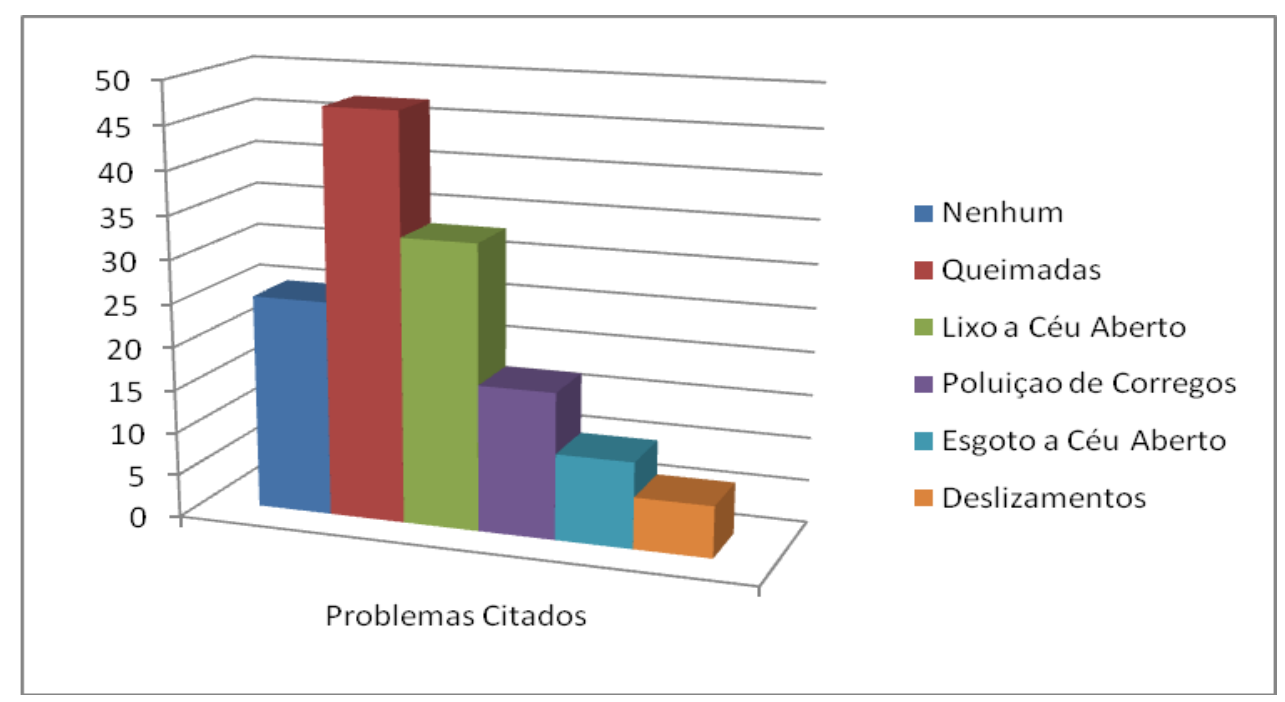

FIGURA 2 - Levantamento de Problemas dos Bairros

De acordo com a Figura 2 o principal problema apontado pelos entrevistados foram as queimadas $30,72 \%$, seguido por lixo a céu aberto, enquanto o deslizamento foi o problema de menor relevância atingindo 3,92\%.

Os questionários mostraram os diferentes níveis de percepção dos entrevistados, haja vista o apontamento de problemas ambientais 


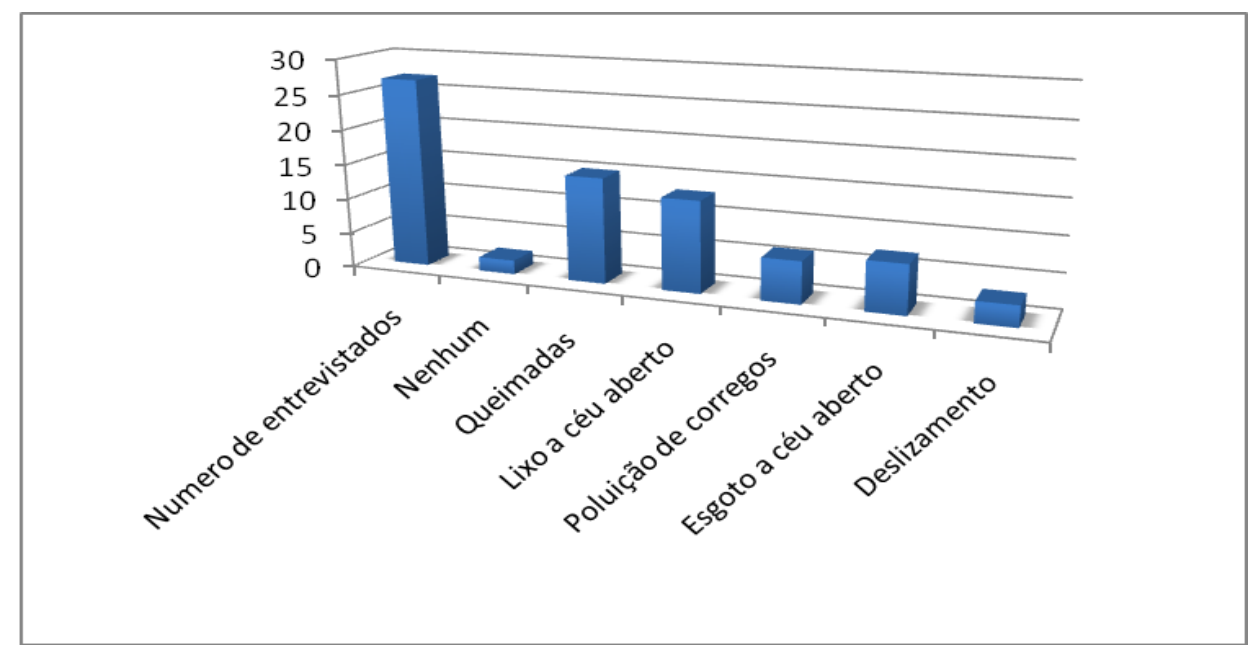

FIGURA 3 - Diferentes pontos de vista em relação aos problemas ambientais existentes na Vila Furquim

É possível observar através da Figura 3 que os moradores deste bairro apontaram problemas distintos para uma mesma realidade. Três dos entrevistados chegaram a afirmar que não havia nenhum problema em seu bairro.

Em relação à responsabilização pelos problemas, $90 \%$ dos entrevistados apontaram a si próprios como responsáveis, porém, porém apontaram as autoridades competentes, como a prefeitura, e ou ONGs, como solucionadoras dos mesmos.

\subsection{Imãs}

Os imãs de geladeira distribuídos no evento, um total de aproximadamente 300, tiveram papel fundamental no processo de consolidação da educação ambiental, pois tinha como função, ao ser fixado na geladeira, remeter as pessoas 5 maneiras de ajudar o meio ambiente dentro de casa.

\subsection{Mudas}

Foram entregues mudas, de espécies nativas da região, sendo elas: Ypê roxo Tabebuia impetiginosa, Angico Branco Do Morro Andenanthera peregrina Ipê amarelo - Tabebuia ochracea, algodão-do-campo - Cochlospermum Regium.
Após a entrega das mudas o entrevistado era encaminhado a assinar um "contrato", se responsabilizando pela muda, assim como à saúde e preservação da mesma, criando assim uma maior responsabilidade do entrevistado com o plantio da muda.

Foram doadas 500 mudas nativas da região, pela Prefeitura de Presidente Prudente em parceria com a Unoeste, sendo todas entregues durante o evento. $O$ objetivo da doação das mesmas era mostrar aos moradores a importância da arborização urbana para a qualidade de vida e incentivar o plantio das mesmas no município de Presidente Prudente.

\section{CONCLUSÃO}

Foi possível observar que a grande maioria dos entrevistados não tinha uma percepção acerca dos problemas ambientais pertencentes á sua realidade, contudo, mostraram-se interessados em ajudar ao meio ambiente.

Notou-se também que o desejo de ajudar acabava esbarrando na falta de informação, haja vista, os questionamentos por parte dos mesmos aos entrevistadores, sugerindo-se assim, a necessidade por realização de projetos de 
educação ambiental, sobretudo em bairros da periferia do município.

\section{REFERÊNCIAS}

FAGGIONATO, S. Percepção Ambiental. 2002.

Disponível em: <http://educar.sc.usp.br>. Acesso em: 6 set. 2010.

FERNANDES, R. S. et al. Uso da percepção ambiental como instrumento de gestão em aplicações ligadas às áreas educacional, social e ambiental. 2006. Disponível em: <http://www.anppas.org.br/encontro_anual/encont ro2/GT/GT10/roosevelt_fernandes.pdf $>$. Acesso em: 5 set. 2010.

PHILIPPI JR., A.; PELICIONI, M. C. F. Educação Ambiental: desenvolvimento de cursos e projetos. São Paulo: Signus Editora, 2002. 350 p.

Dias, G. F. Educação Ambiental. São Paulo:

Gaia, 2008.

$<$ http://www.scielo.br/scielo.php?script=sci_arttext \&pid=S0104$12901998000200003 \&$ lng=pt\&nrm=iso $>$. Acesso em: 5 set. 2010. 